\title{
Sistem Informasi Pelayanan Jasa Wedding Organizer dalam Bentuk Marketplace
}

\author{
Dinda Putri Amelia ${ }^{\mathrm{a}}$, Andreas $^{\mathrm{a}}$, Hartarto Junaedi ${ }^{\mathrm{b}}$ \\ ${ }^{a}$ Departemen Ilmu Komputer, Universitas Pelita Harapan Kampus Surabaya \\ ${ }^{\mathrm{b}}$ Departemen Sistem Informasi, Institut Sains dan Teknologi Terpadu Surabaya \\ E-mail: dindapamelia743@gmail.com, andreas.jodhinata@uph.edu, hartarto.j@gmail.com
}

\begin{abstract}
Abstrak-Acara pernikahan merupakan acara yang umumnya memerlukan bantuan wedding organizer yang akan membantu menyusun dan mempersiapkan acara pernikahan. Mencari wedding organizer yang cocok yang dapat mewujudkan pernikahan impian membutuhkan waktu dan tenaga yang tidak sedikit karena perlu dilakukannya survei seperti ke acara pameran. Resiko yang sering dihadapi oleh calon pengantin setelah menemukan wedding organizer yang cocok adalah penipuan yang dilakukan wedding organizer. Uang yang telah dibayarkan oleh customer kepada vendor sering dibawa lari. Hal ini membuat acara yang telah diimpikan sejak lama menjadi sebuah kenangan pahit. Proses promosi yang dilakukan oleh vendor juga terkesan terbatas karena hanya masyarakat di daerah sekitar lokasi vendor yang dapat dijangkau. Jika ingin menjangkau daerah lain diperlukan biaya dan tenaga yang cukup besar. Perkembangan teknologi yang maju membuat segala hal yang awalnya dilakukan secara offline berubah menjadi online. Maraknya toko online yang berbasis marketplace memungkinkan untuk menjadikan wedding organizer yang awalnya hanya dapat ditemui melalui offline menjadi serba online. Tujuan memasarkan wedding organizer melalui website marketplace akan memudahkan pencarian vendor. Menggunakan website marketplace untuk memesan layanan wedding organizer menguntungkan pihak vendor dan customer. Customer yang mencari wedding organizer tidak membutuhkan waktu sebanyak mencari secara manual karena telah vendor sudah berkumpul menjadi satu di marketplace.
\end{abstract}

Kata Kunci-E-commerce, Marketplace, Wedding Organizer, Wedding Planner

\section{Pendahuluan}

$\mathrm{P}$ ernikahan merupakan momen sakral bagi setiap pasangan untuk mengikat janji sehidup semati. Setiap calon pengantin pasti menginginkan pesta pernikahan yang sempurna sesuai dengan apa yang telah diimpikan. Masa kini calon pengantin lebih memilih untuk menyewa jasa wedding organizer untuk membantu mempersiapkan acara pernikahan. Menggunakan jasa wedding organizer (WO) merupakan langkah yang tepat karena ditangani oleh tenaga professional yang sudah terbiasa dalam mempersiapkan acara pernikahan. Pasangan yang akan menikah biasanya akan memiliki perbedaan pendapat mengenai perlengkapan pernikahan. Pihak WO akan menjadi orang yang memberikan solusi atau jalan keluar dari masalah yang dihadapi oleh calon pengantin.

Banyak pertimbangan yang diperhitungkan oleh calon pengantin sebelum memilih. Paket layanan yang ditawarkan berbeda dari satu wedding organizer dengan yang lain, begitu pula dengan harganya. Mencari wedding organizer biasanya dilakukan dengan mendatangi pameran-pameran yang diselenggarakan di area pusat perbelanjaan. Seringkali saat telah menemukan paket yang cocok, namun budget tidak mencukupi sehingga perlu mencari yang lain. Jika tidak beruntung, maka membutuhkan waktu yang cukup lama hingga menemukan sesuai dengan yang diinginkan dan sedang tersedia pada tanggal pernikahan calon pengantin. Hal ini tentunya akan menghabiskan tenaga, pikiran, dan waktu. Selain itu pembayaran yang dilakukan tanpa pihak ketiga cukup beresiko terjadinya penipuan yang dilakukan oleh pihak WO.

Pihak wedding organizer tentu juga ingin perusahaan mereka semakin dikenal luas dan dapat menarik banyak calon customer. Dapat menarik customer sebanyakbanyaknya dan dari berbagai daerah merupakan tujuan promosi dari setiap perusahaan. Cara yang dilakukan untuk mempromosikan wedding organizer yang paling umum adalah dengan ikut serta dalam acara pameran. Acara pameran biasanya diadakan di mall. Namun tentunya target customer hanya terbatas di daerah mall tersebut dan sekitarnya saja. Jika perusahaan menginginkan jangkauan customer yang lebih luas maka perlu ikut pameran berkalikali di daerah yang berbeda. Biaya untuk mengikuti pameran tentunya tidak sedikit dan akan menghabiskan biaya yang besar jika mengikuti pameran di daerah yang berbeda. Cara promosi dengan menyebarkan flyer selain menambah pengeluaran juga kurang tepat sasaran karena orang yang mendapatkan flyer tersebut belum tentu orang yang sedang mencari $W O$ sehingga biasanya flyer tersebut tidak dibaca dan diabaikan begitu saja.

\section{TEORI PENUNJANG}

\section{A. Wedding Planner}

Pasangan yang akan melangsungkan pernikahan tentunya berharap acara pernikahan berjalan dengan lancar sesuai dengan yang diharapkan. Clare Finnell dalam A History and Analysis of Weddings and Wedding Planning (2018) 


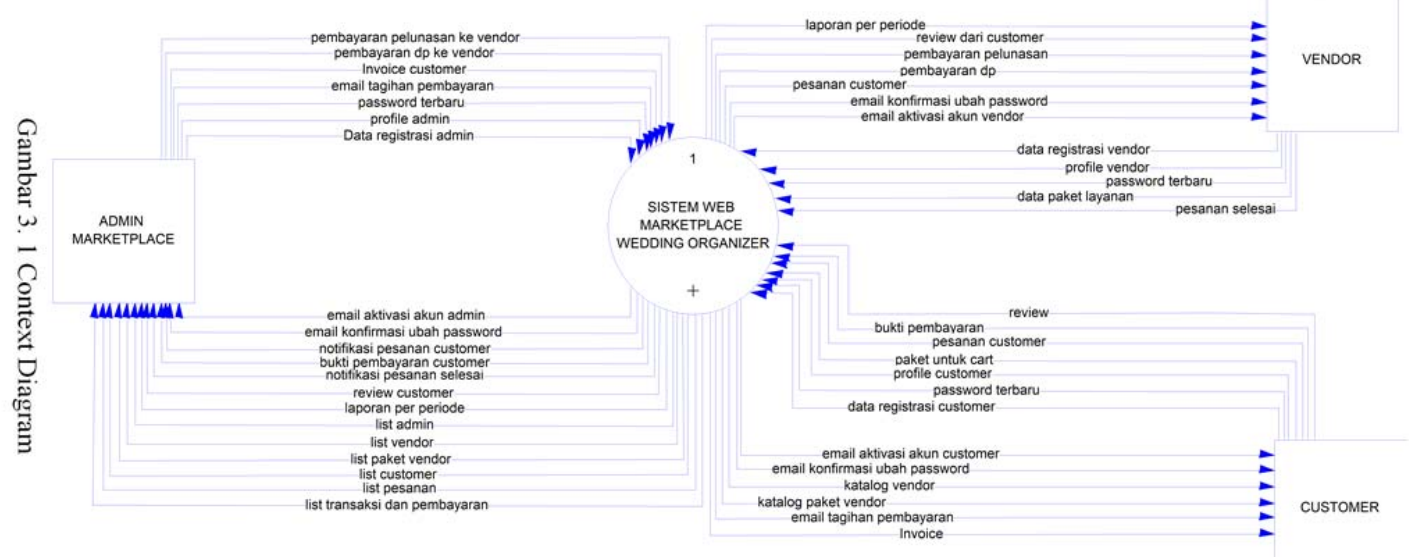

Gambar. 1. Diagram Konteks

menyatakan bahwa "kegembiraan yang dirasakan oleh pasangan yang akan menikah umumnya diikuti dengan tekanan yang dirasakan saat mempersiapkan pernikahan. Wedding planner dan klien haruslah memiliki pemahaman yang sama agar pernikahan yang diinginkan dapat sesuai dengan yang diharapkan."

\section{B. E-Commerce}

Menurut Hossein Bidgoli dalam buku Encyclopedia of Information Systems Volume 2 (2003) bahwa e-commerce merupakan kegiatan menjual dan membeli barang dan jasa melalui internet. Berdasarkan pengertian di atas dapat disimpulkan bahwa peran komputer diperlukan untuk mengakses internet untuk melakukan proses jual dan beli. Munculnya proses jual beli melalui internet mempermudah manusia untuk berbelanja barang ataupun jasa. Perkembangan web dan perangkat mobile yang sangat cepat membuat tradisi belanja konsumen berubah dari offline shopping menjadi online shopping (Genc-Nayebi dan Abran, 2016).

Pada era yang serba digital seperti saat ini, bisnis yang memiliki toko fisik seringkali disertai dengan toko online (Bruno Moriset, 2020). Hal ini tentu akan memudahkan pemilik bisnis dalam menjangkau lebih banyak customer. Berdasarkan penelitian yang dilakukan oleh Harahap dan Amanah (2018), bahwa sebagian besar masyarakat Indonesia di era sekarang lebih memilih untuk berbelanja secara online dibandingkan secara offline. Pemilik toko online tidak mengeluarkan biaya sebesar mengelola toko fisik dikarenakan tidak perlunya membayar pajak bangunan toko.

\section{Marketplace}

Marketplace merupakan salah satu platform yang merupakan tempat dimana penjual memasarkan barang dan jasa kepada konsumen secara online dimana penjual diberi kemudahan untuk melakukan bisnis dengan biaya yang rendah (Amir Mohammad Alaei, 2020). Bergabung pada marketplace memudahkan pebisnis yang baru akan memulai menjual barang secara online, karena tidak perlu membuat situs belanja sendiri.

\section{Metodologi Penelitian}

\section{A. Analisa Sistem}

Pada sistem ini admin marketplace, vendor dan customer hanya dapat mengakses dashboard sesuai dengan masingmasing kategori. User yang sudah membuat akun dapat mengakses sistem setelah memasukkan username dan password. Setelah melakukan login, admin marketplace akan diarahkan ke dashboard khusus admin marketplace, untuk vendor akan diarahkan ke dashboard yang hanya dapat diakses oleh vendor, begitu pula dengan user kategori customer yang akan diarahkan ke dashboard customer yang merupakan website utama yang dapat diakses oleh siapapun.

Bagian admin diberikan akses pada bagian backend yang mengatur keseluruhan sistem website. Admin mengatur dan mengawasi seluruh proses yang dilakukan oleh pihak vendor dan customer. Admin akan dikategorikan menjadi 2 yaitu bagian sistem dan bagian keuangan. Diberikannya kategori admin agar kerja lebih efisien dan cepat serta untuk menghindari kesalahan bagian wewenang.

Admin bagian sistem diberikan wewenang untuk melakukan proses create, read, update, delete akun admin. Admin sistem juga yang mengawasi keseluruhan kerja yang dilakukan oleh vendor. Selain itu admin sistem juga yang akan menangani komplain atau laporan yang diajukan oleh customer terhadap vendor. Secara garis besar, admin sistem menangani keseluruhan proses yang terjadi di dalam website kecuali bagian keuangan.

Admin bagian keuangan bertugas mengawasi dan menangani proses pembayaran yang dilakukan customer. Admin keuangan akan menyimpan track record pembayaran yang sudah dilakukan oleh customer. Setelah layanan yang disewa oleh customer telah diselesaikan oleh vendor, maka admin keuangan akan mengalihkan uang pembayaran customer ke vendor yang sudah dipotong biaya admin. Penggunaan rekening bersama dilakukan agar tidak terjadi penipuan yang dilakukan vendor kepada customer.

Customer bisa melakukan proses create, read, update akun, tetapi tidak bisa melakukan delete. Customer diberikan hak untuk mengisi form pada profil akun yang merupakan informasi pribadi customer. Customer yang melakukan pemesanan dan telah diselesaikan oleh vendor dapat memberikan ulasan untuk menilai kinerja dari vendor. Pembayaran yang dilakukan oleh customer akan diterima 
dan dikonfirmasi oleh pihak marketplace setelah customer mengunggah bukti pembayaran yang telah dilakukan.

Vendor yang telah memiliki akun bisa melakukan update dan delete akun vendor. Informasi tentang profil vendor haruslah jelas sehingga calon customer tidak ragu untuk menyewa vendor tersebut. Setiap vendor bisa melakukan proses create, read, update, delete paket layanan yang nantinya akan ditampilkan pada katalog vendor. Admin vendor akan menangani seluruh proses yang berhubungan dengan vendor.

\section{B. Alat Bantu Analisis Sistem}

\section{1) Diagram Konteks}

Diagram konteks merupakan diagram yang dibuat pertama kali yang selanjutnya akan di-decompose untuk mendapatkan Data Flow Diagram (DFD). Diagram konteks mewakili keseluruhan proses yang terjadi pada sistem website marketplace layanan wedding organizer ini. Pada Gambar 1 diagram konteks ini terdapat 3 entity yaitu admin marketplace, vendor, dan customer yang disatukan dalam satu proses besar yaitu sistem web marketplace wedding organizer. Ketiga entity tersebut memiliki peranan yang berbeda.

\section{2) Data Flow Diagram Level 0 dan Level 1}

Data Flow Diagram level 0 atau DFD Level 0 adalah diagram yang merupakan penjabaran dari proses pada diagram konteks namun dikelompokkan ke dalam proses masing-masing yang dijelaskan lebih rinci seperti pada Lampiran A: Data Flow Diagram Level 0. Dalam diagram ini digambarkan dengan data flow dan data store. Terdapat 6 proses pada DFD Level 0 yaitu proses registrasi, proses kelola admin, proses kelola vendor, proses kelola customer, proses pemesanan, dan proses pembayaran. Pada DFD Level 1 keenam proses yang ada akan dijabarkan lebih detail setiap prosesnya.

\section{3) Entity Relationship Diagram (ERD)}

Entity Relationship Diagram merupakan blueprint dari database yang menggambarkan dari hubungan-hubungan antar entity (Robert A. Patton, 2001). Desain ERD menunjukkan bagaimana sebuah data digunakan pada sebuah proses sistem dana bagaimana data tersebut saling berhubungan (Donald S. Le Vie, Jr.).

4) Physical Data Model (PDM)

Physical Data Model adalah tampilan grafis dari struktur database untuk membantu dalam proses analisa tabel (Business Process Modeling: SAP ${ }^{\circledR}$ Powerdesigner $\AA$ Document Version: 16.6 - 2016-02-22). Physical Data Model merupakan hasil generate dari Entity Relationship Diagram.

\section{IMPLEMENTASI PROGRAM}

\section{A. Homepage}

Saat pengguna mengakses website maka yang pertama akan muncul pada layar adalah halaman home. Pada bagian paling atas home adalah header yang berisi logo dan juga menu. Diatas bagian menu juga terdapat sedikit kontak perusahaan yang disematkan. Dibawah menu terdapat slideshow yang dalam beberapa detik, gambar dan banner akan berubah. Jika di-scroll ke bawah maka akan terlihat daftar vendor yang direkomendasikan.

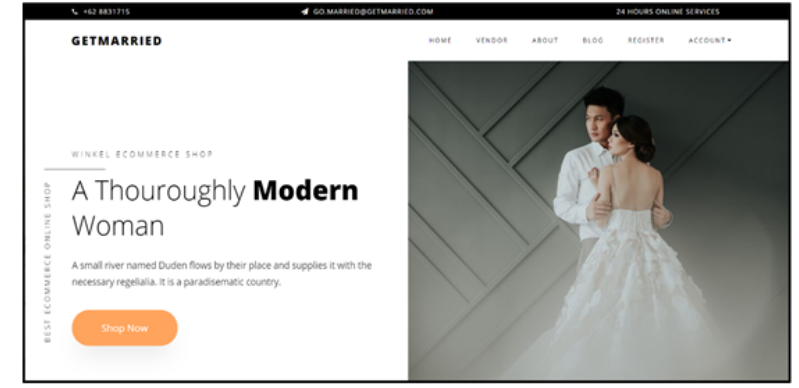

Gambar. 2. Homepage

\section{B. Halaman Vendor}

Halaman vendor merupakan halaman yang menampilkan katalog vendor. Katalog yang ditampilkan diurut berdasarkan huruf alphabet. Di bagian kiri terdapat menu tambahan dimana pengguna dapat mencari vendor berdasarkan kota. Jumlah vendor yang ditampilkan dalam satu baris adalah 4 vendor. Terdapat logo vendor dimana di bagian bawah terdapat nama, kota dan juga rating vendor.

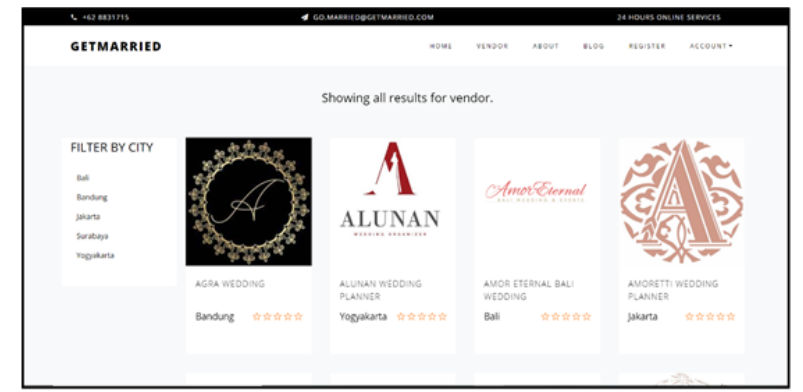

Gambar. 3. Halaman Vendor

\section{Halaman Vendor Single}

Halaman vendor single merupakan halaman yang menunjukkan detail dari satu vendor. Informasi yang dimuat adalah informasi dari vendor yang disimpan pada data store vendor beserta informasi layanan atau paket yang ditawarkan oleh vendor tersebut. Halaman vendor single menampilkan informasi dari vendor yaitu about, package atau layanan yang ditawarkan dan review yang diberikan customer terhadap vendor tersebut.

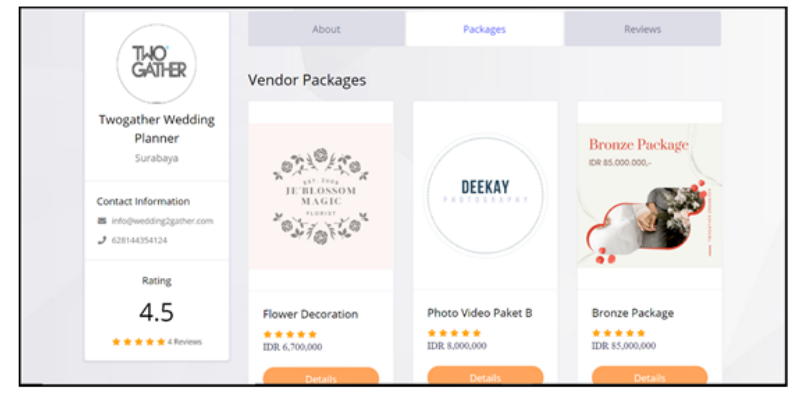

Gambar. 4. Halaman Vendor Single

\section{Halaman About}

Halaman about berisi tentang penjelasan dari website ini yang meliputi sejarah terbentuknya website serta tujuan dibuatnya website. Halaman about memiliki tujuan agar pengguna paham dengan konsep dari website GetMarried ini sehingga dapat menggunakan website ini dengan maksimal. 


\section{E. Halaman Contacts}

Halaman contacts berisi alamat, nomor telepon, email, dan juga map. Disediakannya halaman kontak bertujuan agar pengguna atau calon customer dapat menghubungi pihak marketplace jika ingin bertanya.

\section{F. Halaman My Profile}

Halaman My Profile merupakan dashboard dari customer yang telah login. Halaman ini berisi data atau informasi pribadi dari customer. Mulai dari alamat, kota, jenis kelamin, nomor telepon, dan juga foto profil yang disimpan di data store customer. Jika customer ingin mengubah data pribadi, terdapat tombol edit account yang mana jika diklik maka akan muncul form seperti dibawah ini.

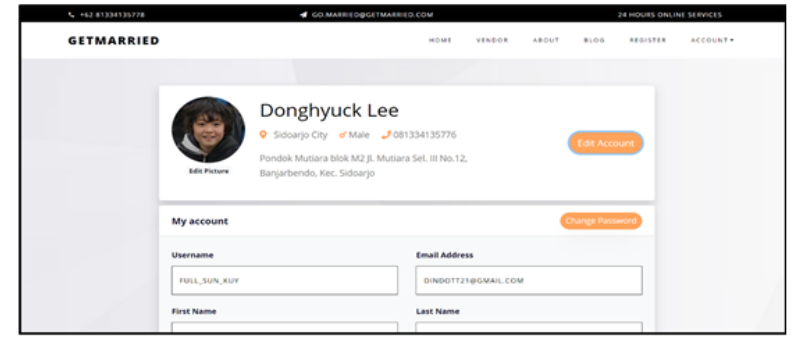

Gambar. 5. Halaman My Profile

\section{G. Halaman Cart}

Halaman cart merupakan halaman yang menampilkan daftar paket yang dimasukkan ke dalam keranjang oleh customer. Paket akan dimasukkan ke keranjang terlebih dahulu sebelum customer melakukan proses checkout.

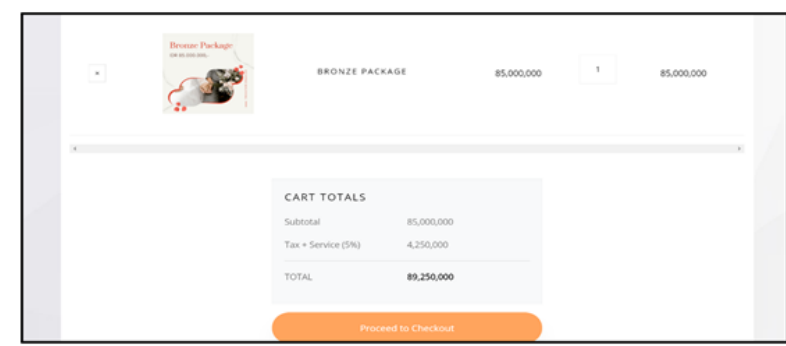

Gambar. 6. Halaman Cart

\section{H. Halaman Checkout}

Setelah ingin melakukan checkout, customer hanya perlu klik button proceed to checkout. Maka akan muncul seperti gambar dimana customer akan diberi informasi sketsa pembayaran yang akan dibagi menjadi 2 yaitu membayar down payment terlebih dahulu sebesar 30\% dari total pesanan. Setelah itu pelunasan akan ditagih pada 1 minggu sebelum acara pernikahan.

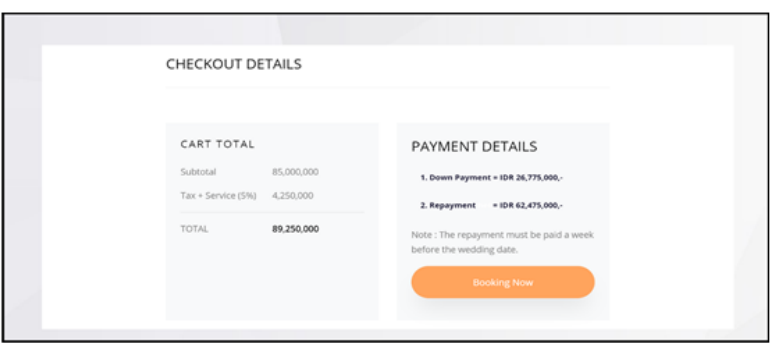

Gambar. 7. Halaman Checkout

\section{Halaman My Order}

Halaman My Order menampilkan pesanan dari customer. Informasi yang ditampilkan adalah kode booking, tanggal booking, harga pesanan dan jumlah yang belum dibayarkan dan status pesanan. Halaman My Order ini dibuat dengan tujuan agar customer dapat melihat progress dari pesanan yang dibuat.

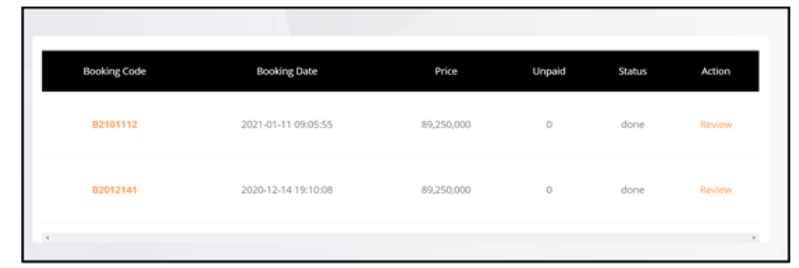

Gambar. 8. Halaman My Order

\section{J. Dashboard Vendor}

Halaman ini tedapat pada dashboard vendor di mana hanya vendor yang sudah login yang dapat mengaksesnya. Berisi daftar paket vendor yang ditawarkan beserta detailnya. Pada tabel daftar menunjukkan judul, harga dan status paket. Selain itu terdapat 3 tombol yang terdiri dari tombol info, edit dan delete. Button info akan membuka halaman baru yang akan menunjukkan detail dari paket seperti gambar. Button edit akan membuka halaman baru berisi form untuk mengubah paket speerti pada gambar. Button delete digunakan untuk menghapus paket.

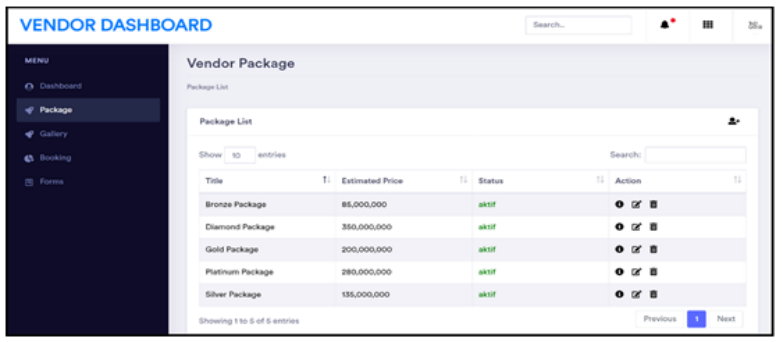

Gambar. 9. Dashboard Vendor

\section{K. Halaman Booking}

Halaman booking menunjukkan daftar dari pesanan yang diterima oleh vendor yang login. Pada tabel daftar terdapat informasi nama customer, tanggal acara, total biaya pesanan, status, dan juga link untuk menampilkan detail.

\section{Halaman Vendor Profile}

Pada halaman vendor profile akan ditampilkan informasi pribadi vendor yang sedang login. Seperti email vendor, alamat, penanggung jawab vendor, kontak, dan lain sebagainya. Selain informasi pribadi vendor, juga terdapat informasi akun bank dari vendor yang berguna saat admin marketplace mengalihkan dana pembayaran yang sudah dilakukan customer. Vendor dapat melakukan pengubahan informasi dengan cara klik icon pensil yang ada pada bagian kanan pada baris account information.

\section{Halaman Add Package/Layanan}

Saat vendor ingin menambahkan paket maka admin vendor perlu klik icon add yang ada pada bagian kanan atas tabel list paket. setelah itu akan muncul form add package. Vendor perlu memasukkan seluruh field agar dapat disimpan. 


\section{N. Dashboard Admin}

Dashboard admin dapat dikses oleh user dengan kategori admin saja. Pada tabel list admin tertera informasi username, orang yang bertanggungjawab, dan posisi admin. Selain itu untuk melihat informasi lebih detail terdapat icon action yang akan membuka halaman baru seperti gambar.

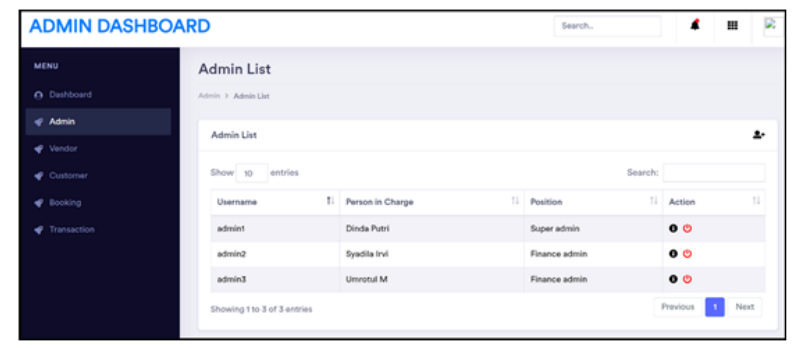

Gambar. 10. Dashboard Admin

\section{O. Halaman List Admin, Vendor, Customer}

Halaman list vendor berisi daftar vendor yang terdaftar di dalam database. Detail dari vendor tersebut akan ditampilkan pada list vendor kecuali email dan password vendor. List vendor yang ditampilkan hanya data yang tersimpan pada data store vendor. Hal ini berlaku juga pada list admin dan customer, yang berbeda adalah data untuk list admin diambil dari data store admin, sedangkan untuk customer diambil dari data store customer.

\section{P. Halaman List Transaction}

Halaman list transaction menampilkan tampilan yang sama dengan list vendor, admin, dan customer. Halaman list transaction berisi data yang tersimpan pada data store booking dan transaction yang terjadi saat terdapat customer melakukan pemesanan. Pembayaran yang dilakukan oleh customer juga akan ditampilkan pada list transaction.

\section{KESIMPULAN}

Kesimpulan dari skripsi sistem informasi pelayanan jasa wedding organizer dalam bentuk marketplace adalah sebagai berikut:

1) Pembuatan website pelayanan jasa wedding organizer akan memudahkan pengguna khususnya calon pengantin yang sedang mencari vendor wedding organizer. Menggunakan website ini akan membantu menghemat waktu dalam melakukan pencarian.

2) Selain bermanfaat bagi customer, pihak vendor juga akan jauh lebih mudah dan lebih hemat biaya dalam memasarkan vendor yang dimiliki. Jangkauan yang luas dan tidak perlu mengeluarkan uang besar untuk biaya akomodasi merupakan keuntungan yang sangat besar.

3) E-commerce saat ini merupakan bisnis yang sangat populer. Acara pernikahan yang tidak akan pernah hilang merupakan bisnis yang menjanjikan. Membuat marketplace wedding organizer yang saat ini masih tidak banyak akan memiliki kemungkinan yang tinggi untuk menguasai pangsa pasar pernikahan.

\section{DAFTAR PUSTAKA}

[1] Alaei, Amir Mohammad, Ata Allah Taleizadeh, and Masoud Rabbani. "Marketplace, reseller, or web-store channel: The impact of return policy and cross-channel spillover from marketplace to web-store." Journal of Retailing and Consumer Services (Pergamon), September 2020: 102271.

[2] Bidgoli, Hossein. "Encyclopedia of Information Systems." Electronic Commerce (Elsevier), 2003: 15-28.

[3] Data Modeling. SAP PowerDesigner, 2016.

[4] Finnell, Clare. "A History and Analysis of Weddings and Wedding Planning." 2018.

[5] Genc-Nayebi, Necmiye, and Alain Abran. "A Systematic Literature Review: Opinion Mining Studies from Mobile App Store User Reviews." 2016.

[6] Harahap, Dedy Ansari, and Dita Amanah. "PERILAKU BELANJA ONLINE DI INDONESIA: STUDI KASUS." Jurnal Riset Manajemen Sains Indonesia (JRMSI) 9 (2018).

[7] Moriset, Bruno. "International Encyclopedia of Human Geography." Edited by Audrey Kobayashi. e-Business and e-Commerce (Elsevier), 2020: 1-10.

[8] Patton, Robert A., Jennifer Ogle, and Travis Laird, "Designing SQL Server 2000 Databases." Chapter 4 - Designing and Creating SQL Server Databases (Syngress), 2001: 127-188.

[9] Pucihar, Andreja, and Mateja Podlogar. "E-Marketplace Adoption Success Factors: Challenges and Opportunities for a Small Developing Countr." January 2005.

[10] Voinov, Alexey. "Conceptual Diagrams and Flow Diagrams." (Elsevier) 2018. 